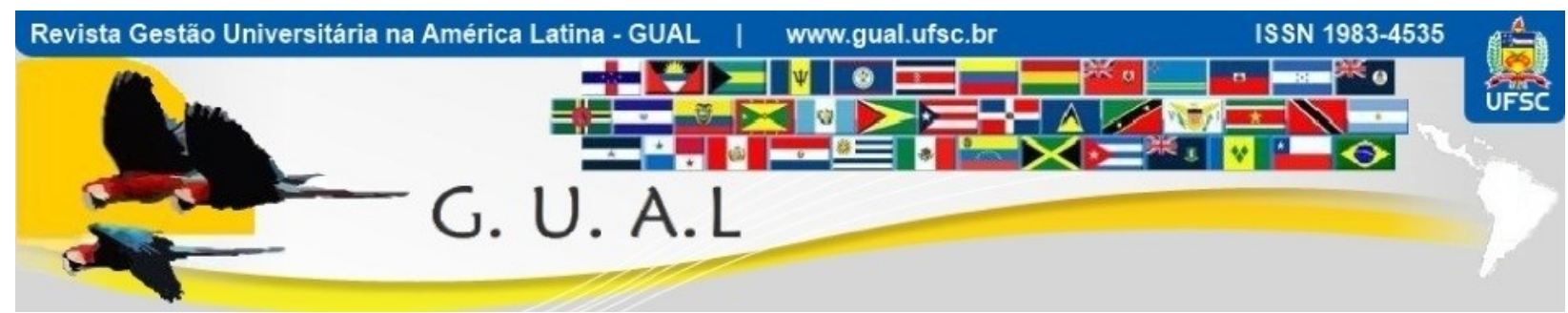

DOI: http://dx.doi.org/10.5007/1983-4535.2017v10n3p59

\title{
PLANEJAMENTO ESTRATÉGICO COMO FERRAMENTA DE GESTÃO NO ENSINO SUPERIOR: ESTUDO DE CASO NA FACULDADE LA SALLE DE LUCAS DO RIO VERDE-MT
}

\section{STRATEGIC PLANNING AS MANAGEMENT TOOL IN HIGHER EDUCATION: A CASE STUDY AT THE COLLEGE LA SALLE LUCAS DO RIO VERDE-MT}

Marisa Claudia Jacometo Durante, Doutora Faculdade La Salle de Lucas do Rio Verde - MT marisa@faculdadelasalle.edu.br

Paulo Renato Foletto, Mestre Faculdade La Salle de Lucas do Rio Verde - MT foletto@faculdadelasalle.edu.br

Adriana dos Reis Silva, Especialista Faculdade La Salle de Lucas do Rio Verde - MT adriana@,faculdadelasalle.edu.br

Nelso Antonio Bordignon, Doutor Faculdade La Salle de Lucas do Rio Verde - MT nelso.bordignon@lasalle.edu.br

Recebido em 25/agosto/2015

Aprovado em 23/maio/2017

Sistema de Avaliação: Double Blind Review

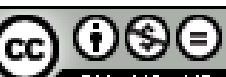

Esta obra está sob uma Licença Creative Commons Atribuição-Uso. 


\title{
RESUMO
}

As Instituições de Ensino Superior Privada encontram-se em um ambiente de expansão, portanto, de ampla concorrência. Por outro lado, possuem diferença significativa dos demais ramos de negócio, pois são proprietárias do capital investido para gerir a atividade, mas não detentoras do produto que 'comercializam', ou seja, a educação. Assim esse estudo teve como objetivo geral analisar o Planejamento Estratégico (PE) como ferramenta de gestão capaz de apoiar a administração da Faculdade La Salle de Lucas do Rio Verde na tomada de decisão. De modo específico buscou-se: a) Analisar o resultado da execução do PE do ano 2012; b) Verificar as estratégias obtidas através das quatro perspectivas do BSC adotadas pelo grupo gestor para o ano de 2013. Para tanto, o desenho metodológico optou pela pesquisa qualitativa, descritiva e documental, sendo o objeto de estudo o PE da IES 2012 e 2013. Os principais resultados indicam que a partir da implantação do PE como ferramenta de gestão a instituição apresentou crescimento e se fortaleceu no mercado. Constatou-se que o PE possibilitou uma visão ampla dos seus pontos positivos e negativos, onde se tornou possível aperfeiçoar e implantar alguns projetos e processos, o que proporcionou melhorias para a IES.

Palavras chave: Planejamento Estratégico. Gestão. Instituição de Ensino Superior.

\begin{abstract}
The Private Higher Education Institutions are in a growth environment, so wide competition. On the other hand, have significant difference from the other lines of business, as are owners of invested capital to manage the activity, but not in possession of the product that 'market', education. So this study aimed to analyze the Strategic Planning (PE) as a management tool able to support the administration of the School of La Salle Lucas do Rio Verde in decision making. Specifically sought to: a) to discuss the outcome of the implementation of Parliament's year 2012; b) Check the strategies obtained through the four perspectives of the BSC adopted by the management group for the year 2013. For this purpose, study design opted for a qualitative, descriptive and documentary, and the PE subject matter of IES 2012 and 2013. The main results indicate that since the implementation of PE as a management tool the institution grew and strengthened in the market. It was found that the EP has enabled a broad view of its strengths and weaknesses, where it became possible to improve and implement some projects and processes, which provided improvements to the IES.
\end{abstract}

Keywords: Strategic Planning. Management. Institution of Higher Education. 


\section{INTRODUÇÃO}

A busca pela eficácia organizacional em uma empresa ou sociedade exerce influência em muitos fatores e a gestão deve reagir a eles. Toda organização deve responder as necessidades de seus consumidores ou clientes, as restrições legais, políticas e as mudanças econômicas e tecnológicas. Os gestores trabalham cada vez mais com um ambiente econômico imprevisível, sendo fundamental reagir rapidamente diante das mudanças nas condições econômicas do país, onde a criação de normas governamentais tem influenciado as ações gerenciais nas práticas que influenciam na forma de uma empresa conduzir seus negócios.

Portanto, a visão de um bom planejamento organizacional vai ao encontro de uma boa administração pelos dirigentes internos na elaboração de um planejamento estratégico (PE), demonstrando sua importância com estratégias em longo prazo na busca pelas informações e os resultados obtidos auxiliando a tomada de decisão.

Sendo assim, Silva (2009) demonstra como o Balanced Scorecard (BSC) como uma moderna ferramenta de gestão, vindo auxiliar na forma de gerir a empresa com indicadores de desempenho baseados em quatro perspectivas: financeira, clientes, processos internos e aprendizado e crescimento.

Neste cenário também se insere as Instituições de Ensino Superior (IES) e, para que ocorram estratégias adequadas necessita de gestão eficiente, e que conheça bem o ramo educacional, pois o ensino deve ser a base para a construção da identidade da pessoa perante a sociedade.

No caso das (IES), possuem uma diferença significativa dos demais ramos de negócio. Elas são proprietárias do capital investido para gerir a atividade, porém, não detentoras do produto que 'comercializam', ou seja, a educação. A IES tem todo o processo de conhecimento com objetivo de ensinar a toda à sociedade, precisa ter excelência no ensino, se destacando muito mais por uma organização de construção do conhecimento, do que apenas uma prestação de serviço. As instituições privadas são organizadas junto ao sistema federal e supervisionadas pelo SINAES, este que é operacionalizado pelo INEP, conforme as diretrizes do CONAES, em ciclos avaliativos, conforme Decreto No 5.773, de 9 de maio de 2006 art. 59.

Em Lucas do Rio Verde-MT a Faculdade La Salle está classificada como faculdade, tendo seus atos de autorização, reconhecimento, habilitações e credenciamentos determinados 
e renovados periodicamente pelo processo de avaliação, não tendo obrigação de manter atividades de pesquisa e extensão de acordo com sua classificação, porém é obrigada a manter o ensino com qualidade e é avaliada de acordo com critérios medidos pelo próprio Ministério da Educação (MEC).

A Faculdade La Salle tem como base primordial desenvolver uma formação crítica para os acadêmicos, com respeito à integridade da pessoa humana, em que a construção do conhecimento se dá de forma participativa valorizando o aprender contínuo. A faculdade neste momento disponibiliza os cursos de bacharelados em Administração, Ciências Contábeis e Direito, cursos Tecnólogos em Gestão da Tecnologia da Informação e Agronegócio, e cursos de Licenciatura em Educação Física e Pedagogia.

Assim, surgiu o questionamento: Qual a real importância da aplicação do Planejamento Estratégico como ferramenta de gestão capaz de apoiar a administração na Faculdade La Salle de Lucas do Rio Verde, sendo uma Instituição de Ensino Superior Privado sem fins lucrativos? Tendo como objetivo geral analisar o Planejamento Estratégico como ferramenta de gestão capaz de apoiar a administração da Faculdade La Salle de Lucas do Rio Verde na tomada de decisão. De modo específico buscou-se: a) Analisar o resultado da execução do PE do ano 2012; b) Verificar as estratégias obtidas através das quatro perspectivas do BSC adotadas pelo grupo gestor para o ano de 2013.

\section{REVISÃO DA LITERATURA}

\subsection{PLANEJAMENTO ESTRATÉGICO}

O Planejamento Estratégico define no futuro, o que a entidade vai fazer e de como serão utilizados seus recursos, ele determina objetivos e metas da corporação. De acordo com Oliveira (2011, p. 4) "o planejamento estratégico corresponde ao estabelecimento de um conjunto de providências a serem tomadas pelo executivo para a situação em que o futuro tende a ser diferente do passado".

Assim, o planejamento estratégico tem o objetivo de analisar uma empresa de vários ângulos, direcionando de forma concreta a solução de problemas que acontecem ou que virão acontecer dentro de uma organização, atuando sobre meio ambiente, tomada de decisões, padrão de comportamento, produtos e serviços que pretendem oferecer, e clientes e mercados que almejam atingir.

Planejamento estratégico é o processo administrativo que proporciona 
sustentação metodológica para se estabelecer a melhor direção a ser seguida pela empresa, visando ao otimizado grau de interação com os fatores externos - não controláveis - e atuando de forma inovadora e diferenciada (OLIVEIRA, 2011, p. 17).

Na maioria das empresas o planejamento estratégico é de responsabilidade do mais alto nível das organizações, e diz respeito tanto a definição de metas, objetivos e diretrizes para garantir o sucesso da empresa, levando em consideração as condições internas e externas das organizações. Através do planejamento estratégico a empresa busca conhecer seus pontos fortes e fracos internos, e conhecer as oportunidades e as ameaças externas.

Ponto forte diferenciação conseguida pela empresa - variável controlável que lhe proporciona uma desvantagem operacional no ambiente empresarial (onde estão os assuntos não controláveis pela empresa).

Ponto fraco é uma situação inadequada da empresa - variável controlável que the proporciona uma desvantagem operacional no ambiente empresarial. Oportunidade é a força ambiental incontrolável pela empresa, que pode favorecer sua ação estratégica, desde que conhecida e aproveitada, satisfatoriamente, enquanto perdura. Ameaça é a força ambiental incontrolável pela empresa, que cria obstáculos à sua ação estratégica, mas que poderá ou não ser evitada, desde que conhecida em tempo hábil (OLIVEIRA, 2011, p. 37).

Diante desses pontos elencados pelo autor a empresa necessita se conhecer e assim poder utilizar melhor seus pontos fortes, eliminar ou adequar seus pontos fracos, aproveitando as oportunidades externas e evitando as ameaças externas. Após os resultados dos trabalhos desenvolvidos o planejamento deverá apresentar resultados conforme descreve Oliveira (2011, p. 38):

Direcionamento dos esforços para os resultados comuns, que sejam do
interesse de todos os envolvidos no processo estratégico da empresa;
Consolidação do entendimento, por todos os funcionários, da visão, dos
valores, da missão, dos propósitos, das macroestratégias, das macro
políticas, da postura estratégica, dos objetivos gerais, dos objetivos
funcionais, dos desafios, das metas, das estratégias, das políticas e dos
projetos da empresa, bem como indicar a elaboração do programa de
atividades das várias unidades ou áreas que integram a estrutura
organizacional; e
Estabelecimento de uma agenda de trabalho por um período de tempo que
permita à empresa trabalhar levando em conta as prioridades estabelecidas e
as exceções justificadas.

Portanto, o planejamento estratégico não deve ser considerado apenas como uma pretensão da empresa, pois necessita o que deve ser feito para que estas pretensões se 
transformem em realidade. Silva (2009, p. 77) entende que o planejamento estratégico é necessário para atingir objetivos específicos rumo à consecução das metas:

Com o planejamento é possível em um só plano diminuir o risco de tomar uma decisão errada, obter uma visão criativa sobre os rumos das empresas, reunir todas as decisões isoladas em um só plano de ação, facilitando a visualização. Sabe-se que diariamente as situações estão diferenciadas, o que torna o amanhã diferente de hoje e o hoje diferente de ontem. Planejar essas diferenças é uma forma de se adiantar e enfrentar os fatos desconhecidos e incertos. Planejar é uma estratégia para sobreviver. As empresas fazem planos estratégicos pelas mesmas razões.

Neste contexto, o planejamento estratégico vem para sistematizar, formalizando processos e procedimentos oferecendo uma visão do futuro, independente da empresa já ser estabelecida ou estar abrindo as portas, pois as organizações necessitam de um processo de planejamento para conduzi-las e indicar a direção ao longo do caminho.

\subsubsection{BALANCED SCORECARD - BSC}

O Balanced Scorecard (BSC) criado em 1992 por Robert S. Kaplan e David P. Norton nos EUA, com objetivo de demonstrar apenas as desvantagens de usar apenas as medidas financeiras, para julgar o desempenho empresarial, incentivando as empresas a medir também fatores como qualidade e satisfação dos clientes.

Conforme Kaplan e Norton (1997) teve sua origem, pois os métodos existentes de avaliação e desempenho já estavam obsoletos com objetivo de avaliar até que ponto os executivos das empresas se sentiam seguros com esses métodos existentes. 3

O Balanced Scorecad é um sistema de informação para gerenciamento da estratégia empresarial. Traduz a missão e a estratégia da organização em um conjunto abrangente de medidas de desempenho financeiras e não financeiras, que serve de base para um sistema de medição e gestão estratégica (SILVA, 2009, p. 97).

Desta forma, para atingir o sucesso empresarial é necessário que a direção seja capaz de difundir uma visão e induzir ações relevantes a fim de alcançar os objetivos estratégicos. De acordo com Fernandes e Berton (2010, p. 192) o BSC é, "uma ferramenta que busca traduzir a visão da empresa em conjunto coerente de medidas de desempenho. Muitas empresas possuem declarações de missão inspiradoras, que fornecem energia e motivação aos funcionários". 
Assim, o BSC permite que as organizações acompanhem o desempenho financeiro, porém inclui os vetores deste objetivo, medindo sob as quatro perspectivas. Permitindo aos gerentes um instrumento para obter êxito competitivo futuro, desde que a diretoria defina uma visão e venha induzir ações para se atingir o sucesso empresarial.

Para um Balanced Scorecard estar bem estruturado não basta uma combinação de medidas financeiras e não-financeiras agrupadas em perspectivas distintas. É necessário que haja a transmissão da estratégia através de um conjunto integrado de medidas. Ele possibilita a comunicação da estratégia criando um modelo holístico. Contudo, para a implementação ser bem-sucedida é necessário identificar os objetivos e medidas certos, caso contrário os investimentos e iniciativas serão desperdiçados (SILVA, 2009, p. 97).

Portanto, o BSC inova com medidores de desempenho de futuro, seus pilares são compostos pelas quatro perspectivas de Kaplan e Norton, perspectiva financeira, perspectiva do cliente, perspectiva dos processos internos e perspectiva do aprendizado e crescimento.

O Balanced Scorecard permite tornar os objetivos financeiros explícitos e ser adequados às organizações nas diferentes fases de crescimento. A Perspectiva financeira de acordo com Kaplan; Norton (1997, p. 49):

Os objetivos financeiros servem de foco para os objetivos e medidas das outras perspectivas do Scorecard. Qualquer medida selecionada deve fazer parte de uma cadeia de relações de causa e efeito que culmina com a melhoria do desempenho financeiro.

A perspectiva do cliente identifica os segmentos de cliente e mercado visados e as medidas do êxito da empresa, identificando os fatores que são importantes na concepção dos clientes e uma exigência e preocupação dentro de quatro categorias tempo, qualidade, desempenho e serviço de apoio, preço e segurança.

"A perspectiva de clientes permite que as empresas alinhem suas medidas essenciais de resultados relacionadas aos clientes - satisfação, fidelidade, retenção, captação e lucratividade - com segmentos específicos de clientes e mercado" (KAPLAN e NORTON, 1997, p. 67).

Na perspectiva dos processos internos, Silva (2009, p.117) explica que "numa IES os processos estão voltados para o cliente - aluno e cada vez mais exigente, que tem suas expectativas iniciadas no momento da matrícula, permeando pela sala de aula durante o seu período de permanência na IES e culminando com a sua colação de grau (formatura). 
Já a perspectiva do aprendizado e crescimento, de acordo com Kaplan e Norton (1997) oferece infraestrutura que possibilita a consecução de objetivos ambiciosos e vetores de resultados excelentes nas outras três perspectivas.

\section{METODOLOGIA}

Este trabalho foi realizado através do método de abordagem indutivo, que de acordo Richardson (2012, p. 35) “a indução é um processo pelo qual, partindo de dados ou observações particulares constatadas, podemos chegar a proposições gerais", ou seja, neste método partiu-se de situações particulares para posteriormente generalizá-las. Quanto à natureza da pesquisa a mesma classifica-se como qualitativa, pois demostrou o processo de aplicação do planejamento no ano de 2012 e identificou os resultados encontrados.

A classificação da pesquisa com base nos procedimentos técnicos foi uma pesquisa Documental e Estudo de Caso, pois a mesma valeu-se de todos os tipos de materiais disponíveis como site, relatório etc., e estudo de caso, pois foi estudado de modo aprofundado o planejamento estratégico da instituição.

O objeto de investigação foi a Instituição de Ensino Superior Faculdade La Salle de Lucas do Rio Verde, que atua no ramo de ensino superior privado presencial, localizada na cidade de Lucas do Rio Verde no Estado de Mato Grosso. Foram analisadas as informações disponibilizadas pela instituição: Utilizou-se o arquivo Planejamento Estratégico da Faculdade La Salle, o sistema SCOPI e o Parecer de Deliberação no 100/2012 - Avaliação do Planejamento Estratégico 2012 e Propostas de Atividades para 2013 para as estratégias obtidas através das quatro perspectivas do BSC adotadas pelo grupo gestor para o ano de 2013.

\section{APRESENTAÇÃO E ANÁLISE DOS RESULTADOS}

\subsection{ANALISAR O RESULTADO DA EXECUÇÃO DO PE ANO 2012}

Para este objetivo específico utilizou-se dados coletados do Sistema SCOPI . Para tanto de acordo com o Parecer de Deliberação n ${ }^{\circ}$ 89/2011 houve alteração no planejamento estratégico referente aos anos anteriores, ou seja, ocorreram algumas mudanças que alteraram alguns objetivos e metas, conforme Bordignon (apud DURANTE, 2011, p.17)

O planejamento estratégico considera o fluxo de informações de baixo para cima. O diferencial deste processo participativo se dá na medida em que há mais chances de se considerar todos os pontos de interesse da Instituição, as 
especificidades dos grupos podem ser manifestadas, o caráter técnico das questões pode ser evidenciado, além do que as propostas da comunidade acadêmica passam a constituir a base do plano da instituição, aumentando-se as condições para a continuidade administrativa. Este processo altera $o$ horizonte e o período de planejamento, não constituindo em amarras para a administração e sim um instrumento útil à mesma, que ao ser revisto periodicamente ou sempre que houver uma mudança importante nas condições externas ou internas da instituição, permite a continuação ou adequação da mesma à alteração de cenários. No planejamento estratégico voltam-se as atenções para as atividades associadas a mudanças ou expansões que causam impacto, demandam grandes esforços e tempo para serem realizadas e que normalmente envolvem muitas pessoas. Desse modo, considerando as quatro perspectivas do BSC e as 10 dimensões do SINAES.

Assim, o Planejamento Estratégico da Faculdade La Salle no ano de 2012 esteve inserido nas quatro perspectivas do $\mathrm{BSC}$, focando, portanto os objetivos e medidas do desempenho organizacional, e de acordo com o Plano de Ação (2012, p. 3):

No período de 2008 a 2011, a Diretoria da Faculdade La Salle promoveu a elaboração do Planejamento Estratégico Institucional, que culminou com a aprovação pelo Conselho Pedagógico conforme RES. N ${ }^{\circ}$. 111/11 de $10 / 10 / 2011$.

Em 2011, o Conselho Pedagógico aprovou, conforme RES. 113/11 de 08/12/2011 o Plano de Desenvolvimento Institucional para o período 20122015. A partir das diretrizes gerais do PDI, é elaborado, anualmente, o Plano de Ações de cada um dos segmentos da instituição, visando o cumprimento dos objetivos e metas estratégicos. Este documento interessa a todos os membros de nossa comunidade acadêmica: aos professores e funcionários, como fundamento em seu ministério acadêmico e profissional; e aos alunos, como instrumento orientador em sua formação pessoal e profissional.

Desta forma, as quatro perspectivas apresentadas para o ano foram: Perspectiva de Aprendizagem e Crescimento que refere-se às melhorias constantes de todo o corpo da IES buscando sempre garantir os princípios da organização como um todo.

A Perspectiva dos Processos Internos, que refere-se à maximização dos processos internos desenvolvidos pela IES como por exemplo plano de carreira dos docentes, normatização de processos, aperfeiçoamento dos processos de avaliação institucional, etc.

A Perspectiva Financeira, nesta perspectiva busca-se as melhorias continuas quanto à infraestrutura, além da busca sustentável econômica financeira.

E por fim, a Perspectiva do Cliente, que refere-se aos processos de marketing institucional, sendo assim, a partir de 2012 foram essas perspectivas adotadas pela instituição.

Assim, na perspectiva aprendizado e crescimento foram estabelecidos 28 (vinte e oito) indicadores, dos quais 16 (dezesseis) foram atingidos, nos quais se destacam os números de 
produções científicas com 280,95\% ficando assim 180,95\% acima da meta, números de ações comunitárias com $250 \%$ atingindo $150 \%$ acima da meta, números de formação continuada corpo técnico $233,33 \%$ atingindo $133,33 \%$ acima da meta, número de projetos comuns elaborados / e executados com 200\% ficando $100 \%$ acima da meta proposta, número de intercâmbios com docentes com 200\% atingindo $100 \%$ acima da meta.

Quanto às metas não atingidas foram 12 (doze) nas quais se destacam Absenteísmo do Corpo docente com 648,25\% negativos, ficando 548,25\% acima da meta, absenteísmo do corpo técnico-administrativo com $361,75 \%$ negativo, ficando $261,75 \%$ acima da meta e o turnover do corpo técnico-administrativo com 136,67\% negativo atingindo 36,67\% acima da meta, estes três indicadores mostram que quanto maior o resultado ultrapassado da meta mais negativo esta meta se torna.

Analisando a perspectiva dos processos internos, encontrou-se que esta possui 8 (oito) indicadores, sendo que 3 (três) metas foram atingidas, 4 (quatro) não atingidas e 1 (uma) meta ficou na tolerância. Para as metas atingidas ressalta-se os números de ações da CIPA com $174 \%$ atingindo $74 \%$ acima da meta, e o número de processos implantados com 133,33\% alcançando 33,33\% acima da meta. Para as metas não atingidas, destaca-se o índice de participação nas avaliações com $75,41 \%$ negativo ficando $24,59 \%$ abaixo da meta e a implantação do recrutamento docente com $75 \%$ negativo com $25 \%$ abaixo da meta, e para as metas com tolerância apresenta a satisfação com o instrumento de avaliação com 98,84\% ficando $1,16 \%$ abaixo da meta.

Sendo assim, observa-se que nesta perspectiva 37,50\% das metas foram atingidas, $50 \%$ das metas não foram atingidas e $12,50 \%$ das metas ficaram no nível de tolerância. Se juntarmos as metas atingidas e as metas com a do nível de tolerância teremos $50 \%$ das metas atingidas, este resultado é possível, pois mesmo não tendo $100 \%$ da meta atingida o seu nível é satisfatório o que pode ser visto como positivo.

Com relação a perspectiva financeira há 11 (onze) indicadores, sendo que 5 (cinco) metas foram atingidas, 5 (cinco) metas não foram atingidas e 1 (uma) meta ficou no nível de tolerância. Para as metas atingidas destaca-se as bolsas do PASE com 200\% alcançando 100\% acima da meta estimada, e a realização anual do plano diretor com $120 \%$ alcançando $20 \%$ acima da meta, e os demais indicadores tiveram suas metas atingidas em 100\%. Para as metas não atingidas destaca-se a folha de pagamento com 131,88\% negativos ficando 31,88\% acima da meta e a inadimplência com $116,8 \%$ negativos sendo $16,8 \%$ acima da meta. E para a meta 
com nível de tolerância a filantropia com 101,58\% negativo, ou seja, 1,58\% acima da meta, estes indicadores mostram que quanto maior o resultado ultrapassado da meta mais negativo esta meta se torna.

Sendo assim, dos indicadores presentes $45,45 \%$ das metas foram atingidas nesta perspectiva, 45,45\% das metas não foram atingidas e $9,10 \%$ das metas encontra-se no nível de tolerância.

Desta forma, observa-se que as metas com nível de tolerância, mesmo não sendo atingidas não significam resultados negativos, pois elas estão num nível aceitável, assim pode-se dizer que 54,55\% das metas foram alcançadas e $45,45 \%$ das metas não foram alcançadas, tendo assim esta perspectiva um resultado positivo.

A perspectiva do cliente observou-se as seguintes informações: de 15 (quinze) indicadores, 8 (oito) tiveram suas metas atingidas e 7 (sete) não tiveram suas metas atingidas. Para as metas atingidas destaca-se, o crescimento de alunos em relação ao ano anterior com $260 \%$ ultrapassando $160 \%$ da meta definida, números de egressos anuais atingidos com $132 \%$ ficando $32 \%$ acima da meta e o índice de satisfação dos colaboradores com 108,34\% atingindo 8,34\% acima da meta. Quanto às metas não atingidas destaca-se o índice de evasão com $153,33 \%$ negativos alcançando $53,33 \%$ acima da meta, pois quanto maior o resultado ultrapassado negativo esta meta se torna, índice de titulação (graduação) com 50,17\% representando 49,83\% abaixo da meta, e a Percepção do uso das avaliações como instrumento de gestão com $90.07 \%$ ficando 9,93 abaixo da meta. Portanto, 53,33\% das metas foram atingidas e 46,67\% das metas não foram atingidas, sendo assim o resultado desta perspectiva é positivo.

De acordo com os resultados encontrados neste objetivo específico, pode-se dizer que o resultado da execução do planejamento estratégico do ano de 2012, segundo as perspectivas foram positivas, pois, três das perspectivas tiveram um percentual significativo de suas metas atingidas e uma perspectiva obteve metade das suas metas atingidas e a outra metade não. Quanto às metas não atingidas mesmo não sendo percentuais elevados, ressalta-se novamente a importância do planejamento estratégico, visto que, as metas não atingidas por algum motivo não obtiveram o seu resultado desejado, o que levanta a questão de nova avaliação para tais metas.

\subsection{ESTRATÉGIAS OBTIDAS ATRAVÉS DAS QUATRO PERSPECTIVAS DO BSC} ADOTADAS PELO GRUPO GESTOR PARA O ANO 2013 
Neste objetivo procurou-se levantar quais seriam os aprimoramentos referente ao Planejamento Estratégico para o ano de 2013. Para que tais mudanças ocorressem foi necessário primeiramente a análise geral do ano de 2012 e assim, a mesma deveria ser exposta ao Conselho Pedagógico (COP) órgão maior da instituição. Após a aprovação por esse órgão, identificou-se quais mudanças foram definidas para o ano de 2013, e de acordo com o Parecer 100/2012, redigido por Foletto (2012, p. 7):

Houve consenso no Grupo Gestor durante o mês de novembro da necessidade de mudança na metodologia, aplicando a inserção de mais uma coluna em nossa matriz estratégica. Hoje, a mesma está composta da seguinte forma:
1- Objetivos Estratégicos
2- Processos Estratégicos
3- Operacionalização / ações
4- Indicadores.

Esta forma de apresentação, apresenta dificuldades na interpretação e na apuração de alguns indicadores, não dinamizando os dados apresentados e tornando o gerenciamento da matriz essencialmente operacional. Após avaliarmos, chegou-se a um consenso de um novo formato de apresentação da matriz estratégica, sendo que a mesma estará assim estruturada a partir de 2013:

$\begin{array}{ll}\text { 1- } & \text { Objetivos Estratégicos } \\ \text { 2- } & \text { Projetos Estratégicos } \\ \text { 3- } & \text { Processos Estratégicos } \\ \text { 4- } & \text { Operacionalização / ações } \\ \text { 5- } & \text { Indicadores }\end{array}$

Ainda de acordo com Foletto (2012, p. 2):

Cabe salientar que para 2013, a proposta é integrar o Plano de Ação ao Planejamento Estratégico, ou seja, o Planejamento Estratégico é também o Plano de Ação para 2013 atendendo as primícias do nosso Plano de Desenvolvimento Institucional (PDI) e por conseguinte nossa Missão, Visão e Princípios Institucionais. Sabe-se que há três tipos de planejamento: o estratégico, o tático e o operacional. Para a alta gestão institucional, cabe pensar o estratégico, porém sem descuidar-se do alinhamento entre o tático e o operacional.

Sendo assim, umas das modificações encontradas para o ano de 2013 é que os processos estratégicos teriam maior prioridade e o planejamento estratégico seria integrado ao plano de ação da IES.

Além dessas mudanças citadas, de acordo com Foletto (2012, p. 9):

O Grupo Gestor estuda ainda a adoção de um "mapa visual" do Planejamento Estratégico, a fim de que ilustre de forma clara e objetiva o panorama organizacional. Constatou-se que uma mesma operacionalização poderá estar muitas vezes ligada a mais de uma perspectiva. Como exemplo, 
pode ser citado o controle da evasão. Este estará incluso na Perspectiva do Cliente, mas também com efeitos na Perspectiva Financeira e na Perspectiva dos Processos Internos.

Desta forma, entende-se que para o ano de 2013 uma operacionalização pode estar ligada a várias perspectivas, o que permite mais ações para que as metas sejam atingidas. A figura 1 representa o Mapa Visual do Planejamento Estratégico.

FIGURA 1 Mapa visual
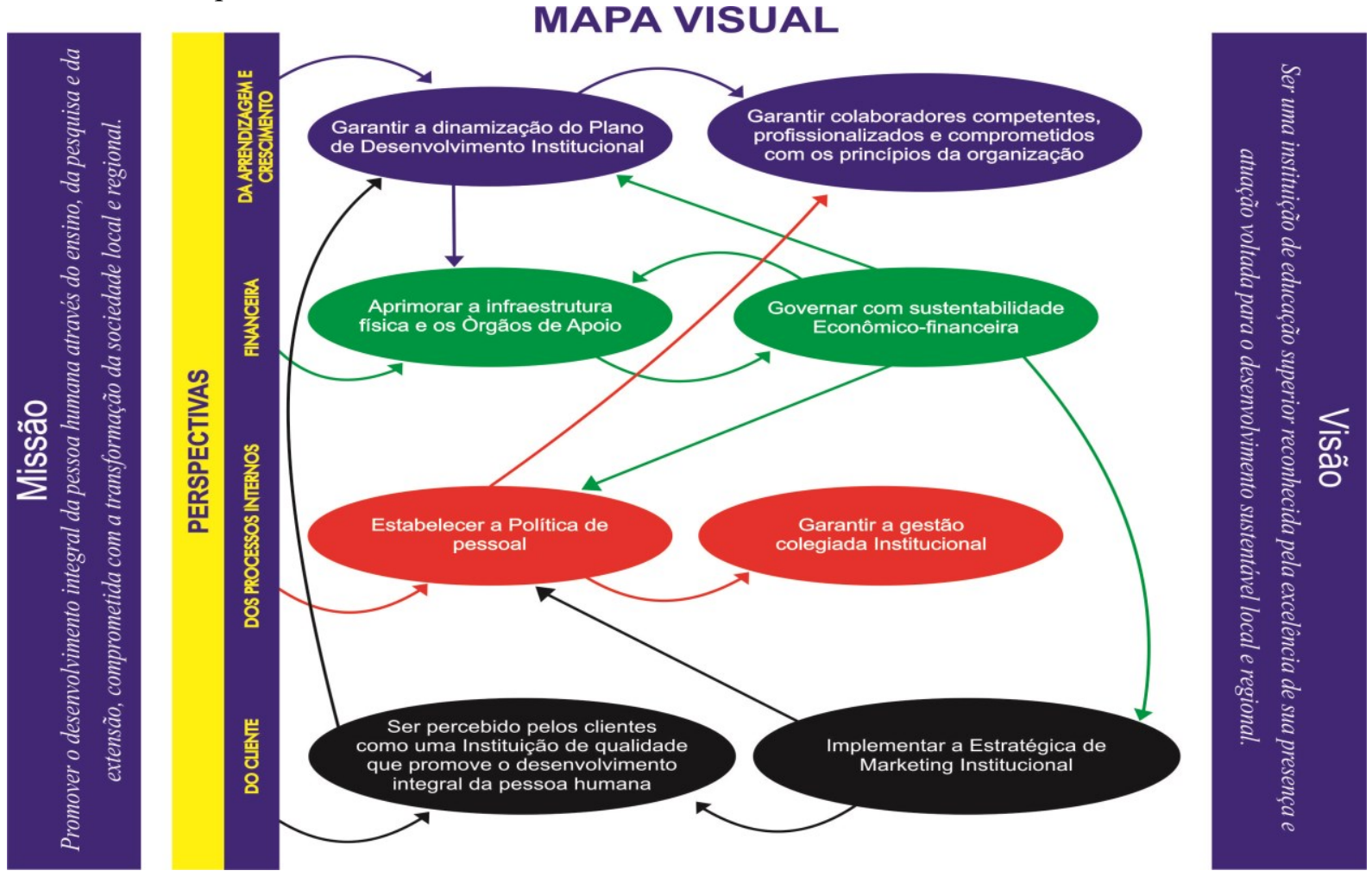

Fonte: Foletto, 2012.

De acordo com os resultados encontrados no ano 2012, procurou-se saber por que motivos a IES deveria de fato mudar ou aperfeiçoar o seu planejamento estratégico, e de acordo Foletto (2012, p. 13):

Tendo o Grupo Gestor avaliado o andamento do Planejamento Estratégico constatou que muitas ações foram concluídas no ano de 2012, outras dependem de um andamento e execução em 2013, outras ainda necessitarão apenas um acompanhamento em 2013, mas teremos as ações que necessitarão de implementação a fim de que o nosso Planejamento Estratégico obtenha êxito. Levando em consideração nossa matriz SWOT, pode-se observar que a IES encontra-se em uma incômoda área de "sobrevivência". 
Para melhor visualização desta informação a figura 2 demostra a situação da IES, sobre a postura estratégica Institucional.

FIGURA 1 Postura Estratégica Institucional
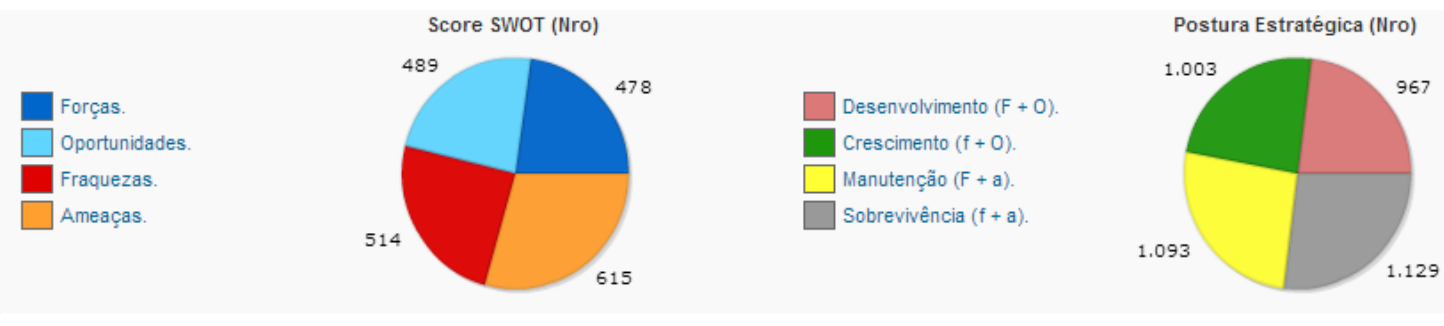

Fonte: SCOPI, 2012.

Tal situação Foletto (2012, p. 13) ainda explica que:

Nosso score SWOT ilustra uma soma de apenas 967 pontos de DESENVOLVIMENTO contra 1.129 pontos de SOBREVIVÊNCIA INSTITUCIONAL. Em outras palavras, nossas fraquezas e ameaças superam em $16,75 \%$ a soma de nossas forças e oportunidades. Daí, a necessidade de efetuarmos cotidianamente um rígido acompanhamento, mas também em termos ousadia de buscarmos novos projetos estratégicos que venham a otimizar a atual gestão institucional.

Sendo assim, o Grupo Gestor entendeu através da análise realizada no ano de 2012 que faz-se necessário aprimoramento de algumas ações e implantações de novas ações para que fosse possível alcançar as metas não atingidas.

Para tanto, especificamente buscou-se saber quais as ações de fato farão parte do planejamento estratégico da IES para o ano de 2013, assim, de acordo com Foletto (2012, p. 13):

Desta forma, propõem-se a este Conselho, os seguintes Projetos Estratégicos a serem trabalhados no ano de 2013: 3.1 - Perspectiva Aprendizado e Crescimento, 3.1.1- Garantir a dinamização do PDI. 3.1.1.1 - Incrementar a cultura de Instituição de Educação Superior Comunitária.3.1.1.2 - Incentivar a integração de projetos comuns de Ensino, Pesquisa e Extensão.3.1.1.3 Incrementar os intercâmbios de docentes, discentes, Programas e Projetos com outras IES, especialmente da Rede La Salle.3.1.1.4 - Integrar o programa de EAD da Rede La Salle.3.1.1.5 - Incentivar programas e projetos de pesquisa da IES. 3.1.1.6 - Dinamizar os programas de Extensão e a inserção com a comunidade externa. 3.1.1.7 - Dinamizar o Plano de Pastoral da Faculdade. 3.1.1.8 - Fortalecer a oferta de cursos de PósGraduação nas áreas de atuação da Faculdade. 3.1.2 - Garantir colaboradores competentes, profissionalizados e comprometidos com os princípios da organização. 3.1.2.1 - Melhorar a qualificação do corpo docente. 3.1.2.2 - Melhorar a produtividade e assiduidade do corpo docente. 3.1.2.3 - Melhorar a qualificação do corpo técnico-administrativo. 3.1.2.4 - 
Melhorar a produtividade e assiduidade do corpo técnico-administrativo. 3.2 - Perspectiva dos Processos Internos, 3.2.1 - Estabelecer a Política de Pessoal. 3.2.1.1 - Implantar o Plano de Carreira do Corpo Docente. 3.2.1.2 Implantar o Plano de Carreira do Corpo Técnico-Administrativo. 3.2.1.3 Normatizar o processo de recrutamento e contratação Docente. 3.2.1.4 Normatizar o processo de recrutamento e contratação do Corpo Técnico Administrativo. 3.2.1.5 - Apoiar as atuações da CIPA. 3.2.2 - Garantir a Gestão Colegiada Institucional. 3.2.2.1 - Aprimorar os processos de gestão acadêmica e administrativa da Faculdade. 3.2.3 - Consolidar o processo de avaliação institucional conforme dimensões do SINAES e o PDI da Faculdade. 3.2.3.1 - Ampliar a cultura avaliativa institucional. 3.3 Perspectiva Financeira. 3.3.1 - Aprimorar a infraestrutura física e os órgãos de apoio. 3.3.1.1 - Executar o Plano Diretor conforme o PDI. 3.3.2 Governar com sustentabilidade econômica financeira. 3.3.2.1 - Aprimorar o planejamento, avaliação e execução dos processos econômicos financeiros da Faculdade, atendendo as Políticas Econômicas e Financeiras da Mantenedora. 3.4 - Perspectiva do Cliente. 3.4.1 - Ser percebido pelos clientes como uma instituição de qualidade que promove o desenvolvimento integral da pessoa humana. 3.4.1.1 - Identificar o perfil do público alvo. 3.4.1.2 - Captar novos alunos. 3.4.1.3 - Aprimorar a política de atendimento aos alunos. 3.4.1.4 - Estabelecer política de atendimento aos egressos. 3.4.1.5 - Fidelizar os alunos. 3.4.2 - Implementar a estratégia de marketing institucional. 3.4.2.1.- Reforçar o relacionamento da IES com os veículos de comunicação da região. 3.4.2.2.- Facilitar as relações e colaborações dentro da Instituição (endomarketing).

Portanto, diversas ações foram adaptadas e outras criadas como, por exemplo, o 3.1.1.3 Incrementar os intercâmbios de docentes, discentes, Programas e Projetos com outras IES, especialmente da Rede La Salle, esta ação é um aprimoramento do ano anterior, 3.1.2.2 Melhorar a produtividade e assiduidade do corpo docente. 3.1.2.3 - Melhorar a qualificação do corpo técnico-administrativo, pois verificando os resultados no ano anterior as metas referentes a esses indicadores foram negativas, desta forma, esta ação já é uma estratégia para melhorar essas metas. O 3.1.1.8 - Fortalecer a oferta de cursos de Pós-Graduação nas áreas de atuação da Faculdade, tal ação não estava descrita desta forma no planejamento estratégico no ano de 2012. Outro levantamento é o 3.4.1.1 - Identificar o perfil do público alvo, esta ação também não era descrita no planejamento no ano de 2012. E por fim se destacam as ações 3.4.1.3 - Aprimorar a política de atendimento aos alunos, 3.4.2.1.- Reforçar o relacionamento da IES com os veículos de comunicação da região. 3.4.2.2.- Facilitar as relações e colaborações dentro da Instituição (endomarketing), as quais são aperfeiçoamento para o ano de 2013.

No ano de 2012 a instituição utilizava o sistema SCOPI, desta forma buscou-se saber se o mesmo seria utilizado para o ano de 2013. E de acordo com Bordignon (2013, p. 41): 
A partir da análise do desempenho do Planejamento Estratégico de 2012, o Grupo Gestor avaliou que se deverá mudar de Sistema de Acompanhamento, isto é, deixar de utilizar o SCOPI, considerando suas inadequações para atender às características do PE da Faculdade La Salle.

Portanto, para o ano de 2013 a IES deixará de utilizar o Sistema SCOPI, visto que, analisou-se que o mesmo não atendia as reais necessidades da IES.

Sendo assim, para 2013 de acordo com Bordignon (informação verbal) será desenvolvido pela TI da IES um Software específico para atender as necessidades da IES, tal Software já está sendo desenvolvido e com a sua finalização prevista para final do mês de setembro de 2013.

Assim, a IES com esta ação estará otimizando o seu planejamento estratégico, visto que a ferramenta que será utilizada será desenvolvida de modo específico para atender a necessidades da IES.

Portanto, as estratégias obtidas para o ano de 2013 foi basicamente o aprimoramento das ações já existentes no Planejamento Estratégico do ano de 2012, além, da criação de novas ações que possibilitam o bom andamento da IES, tendo sempre como foco a sua Missão, Visão e Princípios da Instituição Lassalista.

Desta forma, considera-se este objetivo específico respondido, visto que, foi possível verificar quais as ações foram desenvolvidas para o planejamento estratégico no ano de 2013.

Neste contexto, após analisar o processo de gestão quanto ao planejamento, os resultados obtidos e as propostas apresentadas, diante dos resultados encontrados na pesquisa, considera-se, portanto o objetivo geral respondido, pois, através deste estudo e da pesquisa realizada, verificou-se que a partir da implantação do Planejamento Estratégico como ferramenta de gestão a instituição só tende a crescer e se fortalecer no mercado que continuadamente se torna competitivo.

\section{CONSIDERAÇÕES FINAIS}

Com a elaboração deste trabalho foi possível observar como é importante à utilização de ferramentas de gestão para o bom desempenho das organizações. Dentre estas ferramentas está o Planejamento Estratégico que é um norteador para o atingimento dos objetivos organizacionais. Através dele determina-se a missão, visão, cenários internos e externos, definem-se objetivos, estratégias e ações. Este processo faz com que as empresas direcionem o caminho a percorrer. 


\section{PLANEJAMENTO ESTRATÉGICO COMO FERRAMENTA DE GESTÃO NO ENSINO SUPERIOR: ESTUDO DE CASO NA FACULDADE LA SALLE DE LUCAS DO RIO VERDE-MT \\ DOI: http://dx.doi.org/10.5007/1983-4535.2017v10n3p59}

Após a apresentação e análise dos resultados, considerando a literatura estudada e o problema de pesquisa proposto, constatou-se que o planejamento estratégico possibilitou a IES uma visão ampla dos seus pontos positivos e pontos negativos, onde tornou-se possível aperfeiçoar e implantar alguns projetos e processos, o que proporcionou melhorias para a IES. Assim a real importância da aplicação do Planejamento Estratégico como ferramenta de gestão capaz de apoiar a administração é que permitiu a IES traçar metas e criar ações aperfeiçoando os processos já existentes e criando processos de melhorias contínuas para a IES.

Considera-se que nesta pesquisa a teoria estudada corresponde com o que constatou-se na prática, visto que, com a implantação do planejamento estratégico a IES obteve melhores resultados com suas metas e ações, além de implantar novos projetos e objetivos específicos a serem alcançados. Porém, mesmo com a implantação do planejamento estratégico no momento de desenvolvimento desta pesquisa houve ações e metas não atingidas, mas, contudo, em sua maioria as metas e ações foram atingidas, visto que, todas as perspectivas obtiveram percentuais igual ou maior que 50\%, o que demonstra a importância do planejamento estratégico, pois o mesmo possibilitou resultados satisfatórios para a IES.

Contudo, a IES precisa se atentar para alguns pontos dos cenários, como o Desenvolvimento do cenário tecnológico para inserção de tecnologia na educação (recursos em sala de aula e sistemas de gestão educacionais) obteve uma das menores pontuações no cenário externo - oportunidades, e o que acompanhamos nos últimos tempos é o avanço significativo da tecnologia. Outro ponto importante nos cenários é que a instituição utiliza programas de incentivo para os acadêmicos (ex: PASE, ProUni, FIES, descontos) este também obteve pontuação menor dentro do cenário força interna, porém verificando o cenário de ameaça externa o que obteve maior pontuação são que as pessoas das classes $\mathrm{C}$ e $\mathrm{D}$ não tem condições financeiras para custear graduação ou pós graduação, desta forma fazendo o cruzamento destes dados, tal ameaça poderia se tornar uma força, visto que, a IES tem como força programas de incentivo estudantil.

É importante salientar que as ações e metas desenvolvidas no ano de 2012, serviram de subsídio para as ações e metas do ano de 2013, pois, foi através destes processos que tornou-se possível um aperfeiçoamento para o ano de 2013.

Assim, de acordo com os resultados apresentados faz-se algumas sugestões. A primeira é que a IES realizasse alguns cruzamentos entre os cenários, visto que, é possível 
transformar ameaças em forças, já que a IES possui ações que podem modificar o cenário, como por exemplo, buscando mais incentivos financeiros estudantis para os alunos das classes C e D. Segundo, a IES poderia ter processos de pós-venda para os alunos egressos, mantendo sempre contato com os mesmo para que de certa forma houvesse vínculos não só educativos, mas demonstrando a importância que os mesmos têm para a IES, isso facilitaria as vendas das Pós-graduações ou até mesmo o retorno do aluno para outra graduação, tal ação seria importante, pois, a IES conseguiria fidelizar os seus alunos (clientes). A terceira sugestão seria que houvesse maiores incentivos para os projetos de extensão e pesquisa, pois mesmos não tendo obrigações por não ser classificada como centro universitário, essas ações tornam-se visíveis para a sociedade, o que fortalece a sua imagem diante dos mesmos. No ano de 2012 percebe-se que está meta ficou acima do esperado, porem este resultado se deu devido ao I Congresso Internacional promovido pela IES, desta forma, para o ano de 2013 por não haver o congresso outras ações poderiam ter sido desenvolvidas para que novamente as metas fossem atingidas.

Cabe salientar que o software desenvolvimento especificamente para o PE da Faculdade La Salle está em utilização e atende as demandas, demonstrando seus resultados atuais. No ano 2015 o planejamento estratégico da Faculdade La Salle recebeu o Prêmio Nacional de Gestão Educacional (GEDUC) - categoria Gestão Administrativa.

\section{REFERÊNCIAS}

BORDIGNON, Nelso Antonio. Planejamento Estratégico da Faculdade La Salle - Lucas Sintético. 2013.

DURANTE, Marisa Claudia Jacometo. Parecer de Deliberação nº 89/2011. 2011.

FACULDADE LA SALLE. Plano de Ação. 2012.

FERNANDES, Bruno Henrique Rocha; BERTON, Luiz Hamilton. Administração

Estratégica: da competência empreendedora à avaliação de desempenho. São Paulo:

Saraiva, 2010.

FOLETTO, Paulo Renato. Parecer de Deliberação nº 100/2012 - Avaliação do Planejamento Estratégico 2012 e Propostas de Atividades para 2013. 2012.

KAPLAN, Robert S.; NORTON, David P. A Estratégia em Ação: Balanced Scorecard. 21. ed. Rio de Janeiro: Elsevier, 1997. 
OLIVEIRA, Djalma de Pinho Rebouças de. Planejamento estratégico: conceitos, metodologia e práticas. 29 ed. São Paulo: Atlas, 2011.

RICHARDSON, Roberto Jarry. Pesquisa Social: Métodos e Técnicas. 3. ed. São Paulo: Atlas, 2012.

SCOPI 2013. Disponível em: <http://www.scopi.com.br/pt-BR>. Acesso em 18 set. 2013.

SILVA, Renato. Balanced Scorecard - BSC: Gestão do ensino superior: gestão profissionalizada e qualidade de ensino para instituições de ensino superior privado. Curitiba: Juruá, 2009. 